\title{
O ensino de pragmática por professores nativos e não-nativos de línguas: o que eles sabem e o que relatam estar fazendo ${ }^{1}$
}

\author{
The teaching of pragmatics by native and nonnative language teachers: \\ what they know and what they report doing
}

Andrew D. Cohen

Universidade de Minnesota - Minneapolis, MN, Estados Unidos

$\diamond$

\begin{abstract}
Resumo: $\mathrm{O}$ artigo aborda a questão de como professores não-nativos de uma língua alvo (PNNs) lidam com a pragmática em suas salas de aula. Inicia com uma discussão sobre o que é pragmática. Em seguida, traz aspectos relacionados ao ensino de pragmática, tais como o background do professor, comparações entre ensino de segunda língua (L2) e língua estrangeira (LE) e o potencial da mídia digital e outros meios para prover modelos de comportamento pragmático. Após, é apresentada uma pesquisa internacional, a qual investigou as experiências de PNNs de várias línguas com relação ao ensino da pragmática. Um total de 113 professores relataram o que ensinavam: 30 professores nativos (PNs) e 83 professores não-nativos (PNNs). Foi solicitado a eles que falassem sobre suas experiências como professores de pragmática da L2 e LE. Sendo a pragmática uma mescla de língua e cultura, aos professores foi solicitado que avaliassem seus conhecimentos de pragmalinguística (formas linguísticas) e sociopragmática (conhecimento sociocultural). Ademais, foram instruídos a darem suas opiniões em relação a semelhanças e diferenças entre o ensino da pragmática da LE e da L2, pois essa dicotomia tradicional acarreta uma realidade mais híbrida em um mundo cada vez mais globalizado. Da mesma forma, perguntas foram feitas sobre seus métodos de ensino de pragmática, sua utilização de mídia digital e seu tratamento de diferenças dialetais. Por fim, foi-lhes solicitado que sugerissem áreas nas quais fossem desenvolvidas pesquisas sobre o ensino de pragmática. $\mathrm{O}$ artigo relata os resultados do estudo, incluindo dados sobre o ensino de censuras, sarcasmo e blasfêmia, além do uso de mídia digital e coleta de dados pragmáticos feita por alunos.
\end{abstract}

Palavras-chave: PNs e PNNs; Pragmática da L2 e da LE; Pragmalinguística; Sociopragmática

\begin{abstract}
The paper focuses on how nonnative teachers of a target language (NNTs) deal with pragmatics in their classes. It starts with a discussion of what pragmatics entails. Next, issues relating to the teaching of pragmatics are identified, such as the language background of the teacher, comparisons between second- (L2) and foreign-language (FL) instruction, and the potential role of digital media and other means in providing models for pragmatic behavior. Then, an international survey is presented which probed into the experiences of NNTs of various languages while teaching the pragmatics of their language of instruction. A total of 113 teachers were asked to indicate what they taught with regard to pragmatics, 30 native-language teachers (NTs) and 83 NNTs. They were also asked to report on their experience as teachers of L2 and FL pragmatics (e.g., if they encountered classroom moments when they did not feel like an authority on some aspect of pragmatics, what they did about it). Since pragmatics is a meeting of language and culture, the teacher respondents were asked to assess their knowledge regarding pragmalinguistics (i.e., the language forms) and sociopragmatics (sociocultural knowledge). In addition, they were asked to give their opinion regarding similarities and differences between the teaching of FL as opposed to L2 pragmatics, as this traditional dichotomy gives way to a more hybrid reality in an increasingly globalized world. Similarly, they were asked about their methods for teaching pragmatics (e.g., their use of digital media and their handling of dialect differences). Finally, they were asked to suggest areas in which they would like to see research conducted that would inform the teaching of pragmatics. The paper reports the findings from the study, including statistical differences in reported teaching of criticism, sarcasm, and cursing, as well as in the use of digital media and in having students gather data on pragmatics.
\end{abstract}

Keywords: Native teachers (NTs) and Nonnative teachers (NNTs); L2 vs. FL pragmatics; Pragmalinguistics; Sociopragmatics 


\section{Introdução}

Atualmente, uma atenção cada vez maior vem sendo dada ao ensino da pragmática da língua alvo (LA). Taguchi (2015), por exemplo, fez uma revisão de 58 estudos realizados nos últimos 30 anos, os quais abordaram o ensino de pragmática na LA. Uma das descobertas deste estudo exaustivo foi a de que o ensino explícito de pragmática pode auxiliar na aprendizagem da LA. Consequentemente, o papel dos professores não pode ser subestimado, visto que a pragmática pode ser difícil de ser adquirida por aprendizes. O foco do presente estudo não é frequentemente investigado, qual seja, como professores não nativos (PNNs) de uma L2 ou LE lidam com pragmática em suas salas de aula em âmbito mundial, comparados aos professores nativos (PNs).

Com o surgimento dos estudos sobre World Englishes $^{2}$, os quais dão preferência a variedades locais da LA, poderia ocorrer que a busca por normas da LA fosse considerada desnecessária e, até mesmo, inapropriada. Neste caso, então, os PNNs não precisariam se preocupar em ensinar os padrões da LA. O caso da língua inglesa é geralmente oferecido para apoiar esse argumento. Durante anos, o modelo para a pragmática era, indubitavelmente, o mesmo modelo usado para o inglês como língua estrangeira (ILE), um modelo baseado em normas idealizadas do inglês dos EUA ou Reino Unido. O movimento do World Englishes considera que os EUA e o Reino Unido oferecem um padrão inapropriado para a pragmática (GALLOWAY e ROSE, 2015). Para estes autores, a pragmática deve seguir as normas do local. Além disso, há também o movimento do Inglês como Língua Franca (ILF), o qual, igualmente, considera o Inglês não-nativo como diferente e não deficiente (JENKINS, COGO e DEWEY, 2011). Enquanto o ILE tem suas raízes teóricas sedimentadas em teorias de interferência de L1 e fossilização, o ILF prefere teorias de línguas em contato e evolução. Como consequência, enquanto em ILE o fenômeno de code-switching (alternância de códigos) é visto como evidência de uma lacuna no conhecimento de inglês de um FNN, em ILF é visto como como um fenômeno pragmático bilíngue. Usuários de ILF são vistos como comunicadores habilidosos, que fazem uso de seus recursos multilíngues, os quais não estão disponíveis para FNs monolíngues e que priorizam a comunicação bemsucedida em detrimento de noções sobre o uso "correto" do inglês (JENKINS et al., 2011).

Certamente, é preciso salientar que nem todos os professores de ILE necessariamente adotam os princípios

\footnotetext{
2 Variedades de inglês presentes em uma realidade que o tem como língua internacional (ver KACHRU, Braj B. Introduction. In: Kachru, Braj et al. (org.) The handbook of World Englishes. Oxford: Blackwell Publishing, 2006a, p. 1-16.
}

do ILF. Há aqueles que continuam lecionando de acordo com a norma do falante nativo de inglês, mesmo que aparentemente defendam o ILF. Um estudo de Asmari (2014) sobre as práticas de ensino de inglês entre 200 professores de ILE predominantemente não-nativos na Arábia Saudita, mostrou que enquanto a maioria dos professores não-nativos preferiam o uso de ILF, o que implicaria em expor seus alunos a variedades não-nativas de inglês e, possivelmente, lecionar diretamente essas variedades, na realidade aderiam a normas de nativos em suas aulas, fossem essas inglesas, americanas, canadenses ou australianas, especialmente no registro escrito. Além disso, eles alegadamente buscavam uma pronúncia próxima à do falante nativo.

O presente artigo apresenta um estudo comparando PNs e PNNs em sua abordagem pragmática, começando com uma breve descrição de pragmática e o desafio de comparar PNs e PNNs em termos do que eles ensinam na aula de LA. Após, são apresentados os resultados de uma pesquisa internacional que visou fazer uma sondagem sobre as experiências de PNs e PNNs de várias L2s e LEs. A sondagem investigou o que os PNs e PNNs lecionavam em termos de pragmática, suas experiências como professores de pragmática da LA, sua auto avaliação de conhecimento sociopragmático e pragmalinguístico, sua opinião relativa à distinção entre L2-LE em relação a pragmática, seus métodos para ensino de pragmática da LA e suas sugestões relativas à pesquisa sobre o ensino de pragmática.

\section{O papel da pragmática na língua que os alunos aprendem e usam}

Se os alunos desejam dizer algo a alguém, eles precisam determinar quais são os enunciados apropriados para a situação: o que pode ser dito, a quem, onde, quando e como. Não é mais suficiente sabermos o vocabulário e a gramática. A habilidade pragmática é a habilidade em lidar com o sentido, conforme comunicado pelo falante e interpretado por um ouvinte e intérprete e interpretar os sentidos pretendidos pelos falantes, seus propósitos e os tipos de ações (e.g. fazer um pedido) que estão executando quando falam ou escrevem (YULE, 1996, p. 3-4). A pragmática inclui polidez/impolidez, atos de fala (saudações, agradecimentos, pedidos etc.), estilo conversacional, humor, sarcasmo, provocação, xingamentos, marcadores do discurso, implicaturas conversacionais e deixis (veja COHEN, 2017).

\section{Os desafios em aprender pragmática}

Um estudo que investigou o desenvolvimento de competência formulaica de chinês como L2 em 
nível intermediário entre alunos de ensino superior estadunidenses, em um semestre de mobilidade em Beijing, destacou os desafios em aprender pragmática (TAGUCHI, LI e XIAO, 2013). O estudo concluiu que os aprendizes demonstraram ganhos muito modestos, tanto em adequação como em fluência, em pragmática da língua chinesa. O resultado foi atribuído a sua falta de conhecimento lexical e sintático e de conhecimento sociopragmático (sociocultural) e pragmalinguístico (enfoque na língua). Esses alunos estavam no nível intermediário, porém ainda não tinham desenvolvido a habilidade de produzir frases formulaicas pragmaticamente adequadas para chamar um taxi, sacar dinheiro no banco, barganhar, fazer pedidos em restaurantes, pedir informações sobre sanitários e concluir uma chamada telefônica.

Uma das descobertas interessantes citadas acima (TAGUCHI, 2015) foi a de que o ensino implícito da pragmática foi considerado tão eficaz quanto o explícito, se atividades de conscientização e processamento fossem incluídas. Em suma, fazer com que os alunos primeiramente identifiquem os casos de contexto-formafunção do input e então reforcem esses casos através do processamento consciente produz um resultado positivo. Uma simples exposição ao input, mesmo que tipologicamente incrementada, foi considerada improdutiva em termos de aprendizagem pragmática. Portanto, o objetivo deste estudo foi investigar as possíveis vantagens e desvantagens de PNs e PNNs ao proverem esta instrução explícita ou implícita guiada.

\section{Vantagens entre PNs e PNNs quanto ao ensino da pragmática da LA}

Há alguns anos, Rose (1997) observou que era muito limitada a literatura que tratava do ensino de pragmática por PNNs. Desde então, não houve muito avanço na literatura desta área. Quando muito, houve um esforço em diminuir a importância do fato do professor ser ou não nativo de língua ao lidar com a pragmática da LA. Akikawa (2010), por exemplo, afirmou que ser ou não nativo da língua de instrução é uma questão de menor relevância durante o ensino efetivo de pragmática se comparado à competência linguística e pragmática, além de desenvolvimento profissional apropriado. A posição da autora é a de que a chave para o sucesso do professor reside em ter uma consciência crítica e aceitação da diversidade pragmática. Isto permite que os professores, sejam eles PNs ou PNNs, auxiliem seus alunos a desenvolver uma sensibilidade e tolerância cultural para observar e analisar normas pragmáticas que sejam diferentes das suas e fazerem suas próprias escolhas (AKIKAWA, 2010; veja também ISHIHARA, 2008, 2010).
Há muitos educadores e professores de língua que veem a distinção entre PN-PNNs como um fator de menor importância, especialmente em relação à pragmática do inglês. Ademais, há literatura que corrobora a visão de que é um mito considerar PNs superiores a PNNs (Mahboob, 2010). Vide, por exemplo, obras recentes que descrevem e promovem o status do World Englishes (MATSUDA, 2012; MARLINA e GIRI, 2014). A questão é abordada em vários capítulos destas publicações, atestando que é necessário reconhecer variedades regionais de inglês como legítimas (e.g., Inglês Japonês), sem a aplicação de padrões estadunidenses ou britânicos para definir o que é ou não aceitável. Por exemplo, se empresários japoneses e coreanos estiverem conversando entre si em Seul, é aceitável que utilizem a pragmática de sua L1, em certa medida. Entretanto, aparentemente não há orientações sobre como lecionar as características pragmáticas de um World English, tais como ensinar a variedade japonesa local do inglês para falantes japoneses.

Colocando de lado a questão sobre qual variedade da LA deve ser ensinada, há ainda a dúvida se há vantagens e desvantagens entre PNs e PNNs em relação ao ensino da pragmática da LA. Um estudo conduzido de maneira perspicaz verificou o ensino de pragmática por uma mesma pessoa que estava ao mesmo tempo lecionando francês como PN e alemão como PNN (ASLAN, 2015). Um estudo qualitativo de entrevistas e observações em sala de aula durante um período de seis semanas revelou que as identidades do professor ao lecionar francês como L1 e alemão como LA influenciaram sua cognição de ensino. As observações corroboraram as entrevistas, indicando que o professor possuía diferentes bases de conhecimento para sua língua materna (francês) e não-materna (alemão), sendo que na primeira este conhecimento era implícito e na segunda, explícito.

Ao lecionar alemão, a professora lançava mão de sua proficiência na gramática da língua alemã ao responder de forma bem-sucedida as questões dos alunos, garantindo, desta forma, respeito dos mesmos. Na verdade, na aula de alemão ela apresentava aos alunos análises morfológicas de palavras e conjugações verbais e trazia informações gramaticais, sendo que sua fala era permeada de termos e conceitos metalinguísticos tais como predicados, orações preposicionais e pronomes. Em sua aula de francês, por outro lado, seu uso de terminologia gramatical mostrou ser menos frequente. Na verdade, em uma das aulas observadas, ela explicitamente afirmou que não desejava ser questionada sobre porque uma determinada forma gramatical era exceção à regra. Ela demonstrou dificuldade em explicar a gramaticalidade e adequação de alguns enunciados gerados por alunos. A professora relatou que suas intuições como PN e conhecimento de francês não auxiliavam 
na explicação de fenômenos gramaticais (ASLAN, 2015, p. 257).

É possível que, especialmente em um contexto de ensino de LE, o ensino de pragmática da LA seja um desafio tanto para um PN como para um PNN. Se o professor encoraja os aprendizes de LE a ter interações com falantes nativos (seja ao vivo ou através da internet), talvez essas interações possam levar a um tipo de conscientização pragmática que compense a desvantagem de não estar em um contexto de L2. Embora programas de intercâmbio sejam vistos como meios de colocar os alunos em contato com a pragmática da LA, um estudo recente conduzido por Félix-Brasdefer e Hasler-Barker (2015) revelou resultados interessantes. Os autores constataram que, embora estivessem em um programa extremamente direcionado, organizado por um PN de sua instituição de origem, no qual houve acesso a LA, clube de conversação, passeios, participações em conferências na LA, trabalho voluntário (orfanatos, centros de saúde, entre outros), idas ao cinema e teatro e visitas guiadas a vários locais públicos, os resultados demonstraram poucos ganhos linguísticos por parte dos alunos.

Portanto, há desafios claros associados ao ensino de pragmática da LA, que envolvem tanto o contexto específico para aprendizagem como o conhecimento do professor e sua experiência sobre o ensino da pragmática da LA (ver ISHIHARA, 2014). Certamente, o fator individual de aprendizagem influencia o resultado. Alguns alunos de LE conseguem sucesso através de sua própria determinação para aprender a língua. Pode ser também que um determinado professor, seja ele PN ou PNN, seja experiente em motivar os alunos a aprender a LA, fato que pode compensar o desafio de estar em um contexto de LE sem estar em imersão na LA.

\section{Estudo exploratório sobre o ensino de pragmática por PNs e PNNs}

O interesse em explorar o possível papel da nacionalidade do professor no ensino de pragmática da LA motivou uma pesquisa internacional ${ }^{3}$. A preocupação residia em verificar se, considerando-se a alta competência e habilidade de funcionamento na LA, conhecimento da pragmática da TL, a experiência de ensino e a nacionalidade do professor tinham seus papeis específicos. A principal pergunta de pesquisa foi:

Quais são as semelhanças e diferenças entre os professores nativos e não-nativos quanto ao ensino da pragmática da LA na sala de aula de língua?

\footnotetext{
3 Uma das primeiras pesquisadoras na área da pragmática, Meryl Siegal (Laney College, Oakland, CA), auxiliou na elaboração e construção do instrumento de pesquisa.
}

\section{Instrumentalização}

Um instrumento online de pesquisa foi construído para PNs e PNNs, contendo 20 questões. Houve pequenas diferenças entre as versões dos PNNs e dos PNs e o Survey Monkey foi utilizado para elaboração deste teste. Foi feito um teste piloto com um grupo misto de 15 PNs e PNNs em julho de 2015 e, subsequentemente, modificações foram feitas nas questões. O questionário explorou as seguintes questões:

1. Como os PNs e PNNs lecionam pragmática na aula de LA?

2. Que áreas da pragmática da LA são ensinadas?

3. Até que ponto o professor provê instrução explícita em relação à pragmática,

4. Utiliza mídia digital e aborda diferenças dialetais em pragmática?

5. Como os professores se sentem em serem um recurso para a pragmática da LA?

6. O que os professores fazem caso não tenham segurança quanto à alguns aspectos da pragmática da LA?

7. Qual o grau de conhecimento que os professores julgam ter sobre questões de sociopragmática (formas socioculturais) e pragmalinguística (formas linguísticas) em relação à LA?

8. Qual o grau de relevância na distinção entre L2-LE ao tratar sobre a pragmática da LA?

9. Como as atividades de ensino diferem se o contexto for de L2 ou LE?

10. Como os professores motivam os alunos a aprenderem a pragmática da LA?

11. Em quais áreas da pragmática os professores desejam obter mais informações e resultados de pesquisa?

\section{Amostragem e procedimentos de coleta de dados}

Um convite para responder a pesquisa foi enviado para mais de 100 professores universitários e alunos de pós-graduação, via e-mail. O convite também foi postado no website, no LinkedIn e no Facebook do autor. 113 repostas ao todo foram recebidas, das quais 83 foram dos respondentes da pesquisa sobre os PNNs. Estes eram falantes nativos de 23 línguas (Inglês - 29, Mandarim 10, Vietnamês e Persa - 6 cada, Indonésio - 4, Japonês e Árabe 3 cada, e 14 de outras L1s), os quais eram PNNs de nove LAs em Educacao Superior: Inglês (53), Espanhol (13), Alemão (11), e outras 6. Os respondentes lecionavam língua em média há uns 10.6 anos. Eles atuavam em níveis iniciantes, intermediário e avançado, 
sendo a maioria professor de nível intermediário (66\%) e avançado $(60 \%)$.

Obtivemos 30 respondentes para a pesquisa dos PNs. Estes eram nativos de 7 línguas: Inglês - 5, Japonês - 5, Frances - 1, Espanhol - 2, Catalão - 1, Chinês - 1 e Dinamarquês - 1 e eram PNs de cinco LAs em nível universitário: Inglês ${ }^{4}$ - 21, Japonês - 4, Espanhol - 3, Dinamarquês - 1, e Frances - 1. Os respondentes lecionavam línguas em média há uns 17.2 anos, uma média de 6.6 anos a mais que os PNNs. Eles lecionavam a língua nos três níveis, sendo $75 \%$ em níveis avançados.

Em relação ao contexto de ensino de línguas, 32 dos PNNs lecionavam a LA como LE e 51 como L2. Entre os PNs, 22 lecionavam sua LA como LE e 8 como L2. Alguns professores relataram ensinar pragmática em outros tipos de cursos. Tais cursos incluíam formação de professores, cursos de línguas, cursos de linguística, cursos para propósitos acadêmicos, cursos sobre cultura, sociolinguística e tópicos especiais em pragmática, tais como polidez.

\section{Procedimentos de análise de dados}

O Survey Monkey proveu análise estatística básica (médias e percentagens) para os itens fechados. Análises Chi-square foram utilizadas e o Social Science Statistics ${ }^{5}$ foi utilizado para comparar as respostas dos PPNs e PNs e correlações Pearson utilizando Minitab $17^{6}$ para verificar se os anos de experiência com ensino e os níveis de ensino estavam relacionados à segurança em abordar pragmática na sala de aula. As respostas abertas dos PNs e PNNs foram analisadas quanto ao seu conteúdo.

\section{Resultados}

Com relação as áreas da pragmática que os PNs relataram abordar, houve significativamente mais preponderância de ensino de crítica $\left(\chi^{2}=8.28, \mathrm{p}<.05\right)$ e sarcasmo $\left(\chi^{2}=9.39, \mathrm{p}<.05\right)$. Embora nenhum dos grupos tenha relatado muita utilização de blasfêmias em seu ensino, ainda assim, entre os PNNs, houve mais ocorrências de blasfêmias $\left(\chi^{2}=9.47, \mathrm{p}<.05\right)$. Em outras categorias, os professores demonstraram relativa semelhança em suas respostas. Portanto, o fato da língua ser nativa ou não teve algum impacto no ensino de alguns dos atos de fala mais sutis, tais como expressar sarcasmo e criticar. Além disso, os PNNs relataram ensinar mais aos alunos como interpretar e proferir blasfêmias em comparação aos PNs.

\footnotetext{
4 Um era falante nativo de cantonês em Hong Kong, porem fluente em inglês, língua que leciona.

$5<$ http://www.socscistatistics.com/tests/chisquare/>.

$6<$ http://www.minitab.com/>.
}

Entre os PNNs não houve correlações significativas entre os anos de docência e o ensino de pragmática. Diferentemente dos PNNs, para os PNs houve quatro correlações significativas entre o número de anos de docência e o ensino da pragmática: pedidos de desculpas $(\mathrm{r}=.39, \mathrm{p}<.05)$, reclamações $(\mathrm{r}=.40, \mathrm{p}<.05)$, estilo conversacional $(\mathrm{r}=.47, \mathrm{p}<.01)$, e sarcasmo $(\mathrm{r}=.38, \mathrm{p}<.05)$. Enquanto entre os PNNs houve correlação significativa entre seus relatos de segurança em ensinar pragmática e seus ensinos sobre polidez $(\mathrm{r}=.37, \mathrm{p}<.001)$ e solicitações $(\mathrm{r}=.32, \mathrm{p}<.01)$, não ocorreram correlações significativas entre os PNs.

Com relação ao nível de ensino, os PNNs que lecionam níveis mais altos relataram abordar mais casos de implicaturas $(\mathrm{r}=.33, \mathrm{p}<.01)$ e os que lecionam níveis mais baixos, mais casos de saudações e despedidas $(\mathrm{r}=.32$, $\mathrm{p}<.01)$. Quanto aos PNs, os que lecionam níveis mais altos se ocupam mais com o ensino de críticas $(r=.38$, $\mathrm{p}<.05$ ). Chamamos atenção para o fato de que, embora significativas, a maioria das correlações foram baixas.

Relativamente a seus métodos para o ensino de pragmática, os PNs relataram utilizar muito mais mídia digital do que os PNNs $\left(\chi^{2}=12.85, \mathrm{p}<.01\right)$. Não houve diferenças estatísticas entre os dois grupos de professores quanto ao fato de seu ensino de pragmática ser de modo explícito, tampouco quanto ao percentual de ensino de diferenças regionais e dialetais.

Quanto à naturalidade e facilidade com a qual viam seu papel de provedor de informação sobre as especificidades pragmáticas da LA, 53\% dos PNs relataram facilidade contra $37 \%$ dos PNNs, sendo o chi-square próximo a significância no nível $.05\left(\chi^{2}=5.28, \mathrm{p}=.07\right) .55 \%$ dos PNNs relataram ter alguma facilidade em comparação aos PNs (40\%).

Aos professores foram feitas as seguintes perguntas quanto a sua experiência com pragmática:

Se voce se deparar com momentos da aula nos quais você sente não ter segurança sobre alguns aspectos de pragmática, o que vocêfaz? Indique o grau com o qual você executa as seguintes ações: (frequentemente, às vezes, raramente, nunca)

$\mathrm{Eu}$ assumo minha falta de conhecimento perante meus alunos.

Eu peço que os alunos busquem as informações. Eu ensino o que eu sei e espero que seja adequado.

(Para PNNs)

Eu uso como ponto de partida a pragmática da minha L1 ou de outra língua.

Sobre o que os PNNs e PNs fazem caso se deparam com momentos em aula nos quais não se sentem seguros com algum aspecto de pragmática, ambos grupos rela- 
taram ocasionalmente assumir sua falta de conhecimento para os alunos. Os PNs apresentaram um grau de probabilidade significativamente mais alto ao pedir que seus alunos busquem as informações $\left(\chi^{2}=8.25, \mathrm{p}<.01\right)$. Um número significativamente maior de PNNs relatou ensinar o que sabiam e esperar que isso fosse adequado $\left(\chi^{2}=13.44, p<.01\right)$. Um número razoável de PNNs $(62 \%)$ admitiu utilizar frequentemente a pragmática de sua L1 ou de uma outra língua quando leciona a LA.

Ao comentarem sobre os momentos quando não se sentiam com autoridade sobre alguns aspectos da pragmática, a maioria dos PNNs relatou buscar a resposta com falantes nativos, buscar na internet e com outras fontes e, em seguida, informar a seus alunos. Através de seus comentários os PNNs demonstraram possuir uma série de estratégias para lidar com estas questões, indicando até maior capacidade para responder a pesquisa. Abaixo estão alguns comentários representativos:

- Eu fundamento com pesquisa o que digo aos alunos e quando a pesquisa não é possível, utilizo minhas próprias observações - entretanto, quando minha evidência é somente de observação, eu digo a meus alunos para que não façam generalizações. Se eu não conheço alguma característica pragmática, eu admito e peço a meus alunos que busquem informação. Então pergunto a amigos, que são falantes nativos, caso não haja pesquisa publicada para consultar.

- Explico aos alunos que alguns aspectos de pragmática podem ser percebidos e utilizados de modo diferente, por grupos diferentes, ou mesmo por indivíduos diferentes. Portanto, tal aspecto deve ser visto em situações específicas.

- Eu utilizo informação baseada em pesquisas sobre a pragmática da língua que leciono.

- Se eu não sei, eu informo a eles que estou em dúvida, consulto um falante nativo e dou o retorno a eles no dia seguinte.

- Dada a diversidade do mundo hispano-falante, eu informo aos alunos que eles devem ser mini etnógrafos e observar as normas pragmáticas do local que estão visitando ou de onde estão estudando. Dou como exemplo os problemas de comunicação de Carmen García, uma peruana na Venezuela - ela escreveu um artigo interessante sobre sua dificuldade em fazer um pedido de café num bar. Também discutimos o trabalho de Maria Placencia, no qual compara as normas pragmáticas em Quito, Equador com as de Madrid, na Espanha.

- As pessoas dizem que tenho fluência quase nativa e testes internacionais confirmam que sou "um usuário especialista" de inglês; entretanto, quando a questão é humor, eu não me garanto. Às vezes, sou completamente leigo.

Esses comentários sugerem que os PNNs que responderam essa pesquisa têm experiência com pesquisa e com estratégias para buscar dados. Como podemos observar, uma questão que surgiu foi em relação a situações dialetais em pragmática, tais como para um PNN falante de inglês que leciona espanhol. Outra questão foi a relatada por um PNN altamente competente, o qual não se sente competente com a pragmática da língua para lidar satisfatoriamente com humor. A posição geral foi "na dúvida, pergunte a um falante nativo".

Em relação aos comentários dos PNs, um número significativo comentou sobre utilizar os momentos nos quais não se sentiam seguros como uma oportunidade para buscar dados. No primeiro comentário abaixo, o PN salientou diferenças em normas de comportamento pragmático, de acordo com o país:

$\mathrm{Eu}$ leciono em diferentes países anglófonos (sou estadunidense, mas leciono atualmente na Nova Zelândia), portanto minha confiabilidade sobre pragmática é um ponto que compartilho com meus aprendizes de inglês, pois me sinto um falante nativo do inglês, porém ainda um "estrangeiro".

- Por ter passado três anos na Áustria, um ano na Alemanha e um período na Hungria, e ter tido um pai professor, que repetidamente nos lembrava sobre as variações culturais de expressões verbais, corporais e de atitudes, atiçou minha capacidade de articular questões em vários contextos socioculturais. Parte disso comprova que não sei tudo e que posso estar errado em muitas concepções a fim de não generalizar os conhecimentos que estão enraizados em situações específicas.

- Eu me considero bastante competente em certos registros do japonês, porém registros mais informais ou altamente dialetais eu prontamente admito que estou constantemente aprendendo.

- Sinto que as práticas pragmáticas estão constantemente mudando, assim como as comunidades e que um comando completo tanto da LA como dos contextos socioculturais me parecem uma missão impossível. Até mesmo na minha terra natal, da qual estou distante há dois anos, sinto que não tenho completo entendimento da pragmática da L1.

- Graças ao fato de ter tido formação em pragmática de Inglês como Segunda Língua e ter participado de conferências na área, lido inúmeras publicações sobre o assunto, e realizado pesquisa em pragmática, considero-me bastante 
familiarizado com contextos socioculturais e variações linguísticas.

- Faço o possível para falar com meus colegas nativos em inglês ou busco literatura relevante para depois dar retorno imediato aos alunos.

- Peço aos alunos que pesquisem no COCA ou $\mathrm{MICASE}^{7}$ em busca dos usos. Uma das tarefas de minha aula é pedir que os alunos tragam excertos estranhos de conversas que ouviram.

Estes comentários feitos por PNs revelam a similaridade entre suas abordagens e aquelas dos PNNs quanto às estratégias para obter informação acurada sobre pragmática, seja através de coleta de dados ou através de sua intuição. Além disso, os comentários refletem os desafios que um $\mathrm{PN}$ enfrenta ao lecionar em um país onde é falado um dialeto da sua L1, o qual é diferente do seu, ou em lecionar em um contexto de LE no qual ele está perdendo contato com sua L1.

Aos professores também foi perguntado sobre seu conhecimento de sociopragmática e pragmalinguística da $\mathrm{LA}^{8}$ :

A Pragmática se preocupa com a forma pela qual a lingua é interpretada em um dado contexto sociocultural dentro de uma comunidade linguística alvo. Como você avaliaria seu conhecimento da LA e dos contextos socioculturais nos quais a língua é usada? (Marque todos os itens que se aplicam.)

Muito Familiarizado tanto com a língua como com contextos socioculturais

Mais familiarizado com a língua do que com contextos socioculturais

Mais familiarizado com os contextos sociocul-

turais do que com a língua

Ainda um aprendiz tanto da língua quanto de contextos socioculturais dentro da comunidade alvo

Ocorreram diferenças quanto à familiaridade que os PNNs e os PNs demonstram ter quando em situação de ensino de aspectos sociopragmáticos e pragmalinguísticos da LA. Enquanto somente 37\% dos PNNs se consideraram familiarizados com ambos tipos de aspectos, o dobro dos PNs relataram se sentir muito familiarizados (73\%) $\left(\chi^{2}=34.77, p<.001\right)$. Mais da metade dos PNNs relataram se sentir mais familiarizado com a língua do que com questões socioculturais em comparação à $20 \%$ dos PNs.

\footnotetext{
7 COCA - Corpus of Contemporary American English <corpus.byu.edu/ coca/> e MICASE é Michigan Corpus of American Spoken English $<$ quod.lib.umich.edu/cgi/c/corpus/corpus?page $=$ home $; \mathrm{c}=$ micase $; \mathrm{cc}=\mathrm{mi}$ case>.

8 Pragmalinguística se preocupa em como as formas linguísticas são utilizadas em pragmática; sociopragmática se preocupa com o conhecimento sociocultural necessário para determinar a adequação do comportamento pragmático.
}

Os PNNs que comentaram sobre seu conhecimento de língua e de contextos socioculturais indicaram sua cautela em fazer generalizações em aula com base apenas em suas experiências, visto que as normas para comportamento pragmático apropriado podem variar de acordo com o contexto sociocultural, tanto inter como intra dialetal. Alguns PNNs acrescentaram a ressalva que o que eles ensinam sobre a pragmática da LA é relativo somente às interações de falantes nativos com estrangeiros. Houve também o relato ocasional de especialistas que indicaram adquirir seu conhecimento graças à participação em eventos e em pesquisa que eles e outros haviam realizado. Aqui estão alguns de seus comentários:

- A Itália é um território linguística e geograficamente diverso. Embora meu conhecimento seja substancial, só posso oferecer uma avaliação honesta de sua extensão e reiterar que as possibilidades de contextos socioculturais são infinitas.

- Considero-me bastante familiarizado com a língua japonesa, no entanto quando é um registro mais informal ou altamente dialetal eu diria que ainda estou em processo de aprendizagem.

- Eu digo a meus alunos que o que eu ensino a eles somente se aplica a tratativas com estrangeiros e, mesmo assim, que eles devem seguir a norma que os outros falantes seguem quando em contato com visitantes estrangeiros naquele contexto específico.

Os PNs que comentaram sobre seu conhecimento de língua e contextos socioculturais indicaram que estavam constantemente aprendendo sobre pragmática:

- Embora eu me sinta bem confortável em lecionar a pragmática da minha própria língua, eu admito que há uma grande variedade de dialetos hispânicos e que eu estou constantemente aprendendo sobre outros contextos socioculturais.

- Sou falante nativo da língua que leciono e sou muito analítico sobre a pragmática da minha própria língua devido ao fato de ter sido um aprendiz de L2 de outra língua. Ser capaz de entender as dificuldades que meus próprios alunos encontram - particularmente quando não conseguem explicitar o problema além do entendimento de que algo está errado - é particularmente minha maior contribuição.

- É claro, ainda estou aprendendo e sempre estarei! Mas por ter vivido quase metade da minha vida fora do meu estado e quase uma década fora dos EUA, eu me tornei consciente dos diferentes contextos socioculturais do inglês e eu tento passar essas nuances aos meus alunos, que talvez passem somente um mês em imersão em língua inglesa. 
Estes comentários feitos pelos PNs sobre seu conhecimento sociopragmático e pragmalinguístico reforçam os comentários anteriores, nos quais são relatadas incertezas sobre como lidar com pragmática em sala de aula. Porém, as questões relativas ao ensino em um contexto de LE longe do contato com a L1, além de ter de lidar com diferenças dialetais, foram considerados os maiores desafios enfrentados pelos PNs. Esses comentários também nos lembram que, especialmente em contextos de LE, os PNs estão lidando com questões de multilinguismo.

Em relação à distinção entre LE-L2, foi feita a seguinte pergunta aos professores:

Diz-se que o ensino da pragmática em contexto de LE é mais desafiador do que em contexto de L2, visto que no primeiro caso os alunos não estão vivendo no contexto da língua alvo. De acordo com sua experiência, esta distinção faz sentido para você? (Sim, Relativamente, Não. Justifique)

O contraste entre as opiniões dos PNNs and PNs em relação ao tema não gerou um $\chi^{2}$ com valor $p$ significativo. Enquanto $61 \%$ dos PNNs julgaram a distinção muito relevante e $30 \%$ a julgaram relativamente relevante, $50 \%$ dos PNs a julgaram muito relevante contra $40 \%$ de relativamente relevante.

As seguintes atividades foram consideradas úteis para o ensino de pragmática da LA em contexto de LE:

- Ver segmentos de filmes, vídeos (YouTube e outros) e analisá-los.

- Coletar dados de falantes da LA.

- Fazer dramatizações baseadas em segmentos de vídeos.

- Promover discussões com base em pragmática da LA.

As atividades sugeridas no contexto de L2 para o ensino de pragmática da LA foram muito semelhantes às do contexto de LE. Entretanto, foi relatada uma atividade para o contexto de L2, a saber, analisar amostras de pragmática em uso por falantes da LA:

- Eu peço que meus alunos saiam à campo como etnógrafos e observem tipos específicos de interações: saudações, despedidas entre jovens de ambos os sexos (movimento das mãos, voz, pés, proximidade, expressões verbais) dando e recebendo presentes, chamadas telefônicas, pedidos de informações no campus, expressões de desapontamento, pedir e recusar favores. Estas atividades podem ser escritas, mas, se possível, filmadas e analisadas.

Surgiram inúmeras estratégias utilizadas pelos PNNs e PNs com vistas a motivar seus alunos a aprenderem as normas de pragmática da LA:
- Ao sugerirem aos alunos: se você quer parecer natural e, principalmente, mais polido, você precisa aprender a pragmática da LA.

- Com meus alunos de espanhol intermediário e avançado não preciso motivá-los para que se interessem em aprender a pragmática do espanhol. Eles geralmente consideram as normas sociais fascinantes! Em parte, pode ser porque nas outras aulas os professores não falam sobre pragmática, portanto é algo novo para eles. Além disso, há um componente prático em aprender pragmática, que acho que eles reconhecem.

- Através de materiais relevantes, especialmente música e cinema russos. Se eles gostarem de algo, se sentirão motivados para entender. Além disso, enfatizo como os falantes nativos reagiriam quando alguém se porta de uma forma pragmaticamente inadequada, o que espero os motive a serem conscientes.

- Eu digo a eles que para ser um falante competente é necessário ser apropriado, além de acurado.

- Eu faço questão de que meus alunos de alemão como LE tenham a oportunidade de observar interações reais (filmadas, se possível) entre pessoas que falam a LA; desta forma, eles se dão conta de que há pessoas como eles, que observam as normas linguísticas e sociais que eles estão aprendendo.

- Eu falo a meus alunos de inglês como LE aqui na Itália sobre minhas experiências interacionais com falantes nativos. Se houver alunos internacionais em aula eu sempre peço que eles falem sobre como "sua maneira de fazer as coisas" difere da nossa e quais problemas isso poderia acarretar.

É encorajador ver, a partir destes comentários, que tanto os PNNs como os PNs estão interessados em motivar seus alunos para se tornarem mais versados na pragmática da LA. Especialmente em áreas de comércio e serviços, se os alunos forem pragmaticamente apropriados, eles poderão obter um melhor preço em algum item no mercado ou simplesmente ter uma interação mais agradável. O uso de humor ou mal-entendidos como modo de manter os alunos motivados é indicado, visto que os alunos gostam de ser entretidos, mas também de aprender e reter melhor o que foi aprendido quando os momentos em aula são agradáveis.

Tanto os PNNs como os PNs expressaram um desejo em ter mais acesso à informação sobre pragmática e resultados de pesquisas nas seguintes áreas:

- Humor, sarcasmo, censuras e blasfêmias: estes conteúdos geralmente estão fora do currículo mas são parte integrante de uma cultura. São atos de fala que motivam os alunos a aprenderem. 
- Expressões de solidariedade e compaixão.

- Interação com diferentes gerações de falantes em uma reunião familiar.

- Eufemismos para coisas como idade, sexo e morte.

- Como elaborar perguntas durante as aulas, em conferências e no trabalho.

- A pragmática das discussões online que envolvem vários participantes usando a mesma língua.

- A pragmática da comunicação diplomática.

- A pragmática do Inglês como Língua Franca e, especialmente, a pragmática do mundo dos negócios.

- A conexão entre gramática e pragmática: a relevância dos recursos de um sistema linguístico.

Esse conjunto final de comentários demonstra o quão experientes foram os PNNs e PNs em relação às áreas nas quais a pragmática atua, tais como conversas informais, eufemismos, condolências e interações com pessoas de diversas faixas etárias. Outros comentários incluíram áreas que podem ser muito instrutivas para professores, tais como saber quais tópicos são ou não sociopragmaticamente apropriados para serem trazidos para certos contextos (por exemplo, quanto uma casa nova ou carro custou, quanto é o salário de alguém, etc.) e também distinguir o comportamento normativo para a comunidade da LA do comportamento idiossincrático.

\section{Discussão e conclusões}

Este artigo apresentou um problema que talvez não tenha recebido muita atenção na literatura, qual seja, as maneiras pelas quais os PNs e PNNs diferem e se assemelham ao abordarem a pragmática da LA em suas aulas. Enquanto os PNs e PNNs compartilham muitos dos desafios ao ensinar a pragmática da LA há, entretanto, um fator relacionado aos PNNs: estes demonstraram mais insegurança ao ensinar a pragmática da LA. Os resultados sugerem que as intuições sobre pragmática podem ajudálos a ensinar os alunos a serem adequadamente críticos e sarcásticos e a responder aos comentários críticos e sarcásticos. A ressalva aqui é que confiar na intuição do falante nativo pode ser uma prática equivocada, o que talvez explique porque os PNNs e PNs indicaram que colhiam dados de outras fontes se estivessem em dúvida sobre alguma área da pragmática da LA.

Os PNs também indicaram usar mais mídia digital pois, pelo fato de serem falantes nativos, o uso da mídia da LA se torna mais fácil. Além disso, os PNs também solicitaram mais que seus alunos fossem a campo coletar dados quando estavam em dúvida em comparação aos PNNs, embora ambos os grupos tenham usado essa estratégia. O que foi encorajador sobre esse resultado é que ele indica que os PNs não estavam apenas contando com suas intuições.

Os PNNs relataram ensinar mais palavrões do que os PNs, o que pode ser uma área importante para os alunos dominarem. Um caso à parte seria o de alunas em estudos de imersão, em culturas nas quais devem entender situações de cantadas, para sua própria segurança. Os PNNs também admitiram lançar mão de sua L1, quando não estavam seguros da pragmática da LA, o que poderia se tornar fonte de equívoco caso ocorresse uma transferência negativa durante o processo (ver ISHIHARA e COHEN, 2014). Ademais, a pesquisa forneceu sugestões de como motivar os alunos a estudar a pragmática da LA e também como indicação de quais áreas da pragmática os professores necessitam de mais informação e pesquisa.

O presente estudo é, sem dúvida, um esforço preliminar. Embora tenha um escopo internacional, a amostra foi relativamente modesta. Em virtude de ser uma amostra de professores que se voluntariaram para responder, o estudo revelou um grupo mais experiente em relação ao ensino de pragmática da LA. É possível que professores com menos conhecimento de pragmática tenham se recusado a responder. Além disso, a flutuação nas respostas serviram como indicadores de que é difícil de se chegar a um consenso neste tipo de levantamento. Tanto os PNs como os PNNs falaram de seus lugares, especialmente nas respostas abertas. Eles representaram não somente línguas diferentes, mas também regiões diferentes do mundo. Uma outra limitação foi relativa ao fato da proficiência na LA dos PNNs não ter sido avaliada, uma tarefa que exigiria instrumentos em várias línguas. Sem dúvida, ter tido conhecimento do grau de proficiência deles em suas respectivas LAs teria ajudado na interpretação dos dados, a fim de distinguir as questões entre PN-PNNs de outros tipos de questões. Por fim, não podemos esquecer que os relatos sobre as questões pragmáticas não necessariamente refletem a fidedignidade de como estas questões foram abordadas em sala de aula.

Apesar das limitações do estudo, ele serve como um exercício sobre como lidar com o ensino de pragmática em sala de aula. Como vem ocorrendo um aumento crescente no interesse em lecionar pragmática, urge a necessidade de envidar esforços para apoiar os PNs e PNNs (ver Cohen, no prelo).

Com relação a pesquisas futuras, seguramente há necessidade de ampliar a base de dados através de uma amostra mais sistemática de respondentes, advindos de todas as partes do mundo, além de refinar as questões que foram colocadas para os professores. Com relação à questão pedagógica, há mais a ser feito para desenvolver atividades de sala de aula que auxiliariam no ensino da pragmática da LA, nas áreas menos abordadas e mais desafiadoras. 
Os resultados desta pesquisa aparentementemente demonstram a visão de que há diferenças entre PNPNNs que podem surgir na aula de LA, fato que justifica uma discussão sobre que medidas devem ser tomadas para lidar com essa questão. A preocupação é lidar com aquelas áreas da pragmática nas quais os PNNs não se sentem confortáveis (blasfêmias, sarcasmo, humor etc.). $\mathrm{O}$ fato de ser um PNN pode fazer com que os professores se sintam ainda mais conscientes da necessidade de aprender a pragmática da LA. Por exemplo, tanto os PNNs como os PNs podem se beneficiar de resultados de pesquisa sobre normas pragmáticas. E mesmo que os livros-textos abordem essas areas da pragmática, os exemplos podem não refletir o comportamento normativo corrente (COHEN e ISHIHARA, 2012). Ambos grupos de professores podem também se beneficiar da comparação entre normas pragmáticas de diferentes dialetos, uma vez que os comentários dos PNs revelaram que estes não necessariamente têm consciência das normas da LA para a pragmática em outros países onde sua L1 é falada.

\section{Referências}

AKIKAWA, K. Teaching pragmatics as a native speaker and as a non-native speaker. In: BRADY, B. (Ed.). WATESOL NNEST Caucus Annual Review, v. 1, p. 43-69, 2010. <https://www. academia.edu/816235/StudePNs_appraisal_of_their_native_ and_non-native_English-speaking_teachers $>$.

ASLAN, E. When the native is also a non-native "retrodicting" the complexity of language teacher cognition. The Canadian Modern Language Review, v. 71, n. 3, p. 244-269, 2015.

ASMARI, A. R. Redefining pedagogical priorities: An investigation of EFL teachers' perceptions towards teaching English as a lingua franca in the Saudi higher education context. Journal of Education and Practice, v. 5, n. 28, p. 81-93, 2014.

COHEN, A. D. Developing pragmatic ability: Insights from the accelerated study of Japanese. In: COOK, H. M.; HIJIRIDA, K.; TAHARA, M. (Ed.). New trends and issues in teaching Japanese language and culture. (Technical Report \#15). Honolulu, HI: Second Language Teaching and Curriculum CePNer, University of Hawaii at Manoa, 1997. p. 137-163, 1997.

COHEN, A. D. From L1 to L12: The confessions of a sometimes frustrated multiliterate. In: BELCHER, D.; Connor, U. (Ed.). Reflections on multiliterate lives. Clevedon: Multilingual Matters, 2001. p. 79-95.

COHEN, A. D. (forthcoming). Learning pragmatics from nonnative language teachers. Bristol, England: Multilingual Matters.

COHEN, A. D. Teaching and learning second language pragmatics. In: HINKEL, E. (Ed.). Handbook of research in second language teaching and learning. New York: Routledge. 2017. v. 3. p. 428-452.
COHEN, A. D.; ISHIHARA, N. Pragmatics. In:TOMLINSON, B.; MASUHARA, H. (Ed.). Applied linguistics applied: Connecting practice to theory through materials development. London: Continuum, 2012. p. 113-126.

FÉLIX-BRASDEFER, J. C.; Hasler-Barker, M. Complimenting in Spanish in a short-term study abroad context. System, v. 48, p. 75-85, 2015.

GALLOWAY, N.; ROSE, H. Introducing global Englishes. London \& NY: Routledge, 2015.

ISHIHARA, N. Transforming community norms: Potentials of L2 speakers' pragmatic resistance. In: HOOD, M. (Ed.). Proceedings of the 2008 Temple University Japan Colloquium on Language Learning. Tokyo: Temple University Japan, 2008. p. 1-10.

ISHIHARA, N. Maintaining an optimal distance: Nonnative speakers' pragmatic choice. In: MAHBOOB, A. (Ed.). The NNEST lens: Nonnative English speakers in TESOL. Newcastle upon Tyne: Cambridge Scholars Press, 2010. v. 1. p. 32-48.

ISHIHARA, N. Teachers' pragmatics: Knowledge, beliefs, and practice In: ISHIHARA, N.; COHEN, A. D. Teaching and learning pragmatics: Where language and culture meet. Abingdon, England: Routledge, 2014. p. 21-36.

ISHIHARA, N.; COHEN, A. D. Learners' pragmatics: Potential causes of divergence. In: ISHIHARA, N.; COHEN, A. D. Teaching and learning pragmatics: Where language and culture meet. Abingdon, England: Routledge, 2014. p. 75-96.

JENKINS, J.; COGO, A.; DEWEY, M. Review of development in research into English as a lingua franca. Language Teacher, v. 44 , n. 3, p. 281-315, 2011 .

MAHBOOB, A. The NNEST lens. In: MAHOOB, A. (Ed.). The NNEST lens: Nonnative English speakers in TESOL. Newcastle upon Tyne, UK: Cambridge Scholars Press, 2010. p. 1-17.

MARLINA, R.; GIRI, R. A. (Ed.). The pedagogy of English as an international language: Perspectives from scholars, teachers, and students. Cham, Switzerland: Springer International, 2014.

MATSUDA, A. (Ed.). Principles and practices of teaching English as an international language. Bristol, UK: Multilingual Matters, 2012.

ROSE, K. Pragmatics in teacher education for nonnativespeaking teachers: A consciousness-raising approach. Language, Culture and Curriculum, v. 10, n. 2, p. 125-138, 1997.

TAGUCHI, N. Instructed pragmatics at a glance: Where instructional studies were, are, and should be going. Language Teaching, v. 48, n. 1, p. 1-50, 2015.

TAGUCHI, N.; Li, S.; XIAO, F. Production of formulaic expressions in L2 Chinese: A developmental investigation in a study abroad context. Chinese as a Second Language Research Journal, v. 2, p. 23-58, 2013.

YULE, G. Pragmatics. Oxford, UK: Oxford University Press, 1996.

Recebido: 10 de abril de 2017

Aprovado: 23 de maio de 2017

Contato:

Andrew D. Cohen <adcohen@umn.edu> 